\title{
A REFORMULAÇÃO DOS CURSOS DE LICENCIATURA DA UFG: CONSTRUINDO UM PROJETO COLETIVO ${ }^{1}$
}

\author{
João Ferreira de Oliveira ${ }^{2}$ \\ Luiz Fernandes Dourado \\ Valter Soares Guimarães
}

\section{RESUMO}

Este artigo aborda a reformulação curricular dos cursos de licenciatura. Os autores, a partir da análise crítica da legislação vigente sobre a formação de professores e da experiência de reformulação desenvolvida na Faculdade de Educação da UFG, indicam um caminho possível para a construção coletiva de um projeto de formação de professores.

Palavras-chave: reformulação curricular, formação de professores, cursos de licenciatura.

O presente artigo visa contribuir com a discussão acerca da reformulação curricular dos cursos de licenciatura, particularmente da Universidade Federal de Goiás (UFG). O texto está estruturado em três tópicos: a) repensando a formação de professores nos cursos de Licenciatura da UFG; b) componentes curriculares fundamentais para a elaboração de projetos para as diversas licenciaturas; c) proposta de trabalho para a reformulação curricular dos cursos de licenciatura. Os autores, com base na análise crítica da legislação

\footnotetext{
${ }^{1}$ Artigo recebido em 15/7/2003 e aprovado em 27/8/2003.

${ }^{2}$ Os autores são professores da Faculdade de Educação da UFG. João Ferreira de Oliveira [e-mail: joaofo@terra.com.br], Luiz Fernandes Dourado [e-mail: douradol@terra.com.br] e Valter Soares Guimarães [e-mail: valtersg@terra.com.br].
} 
196 OLIVEIRA, J. F.; DOURADO, L. F.; GUIMARÃES, V. S. - A reformulação...

vigente e dos embates que se processam na área, pretendem contribuir com a construção de um projeto coletivo visando à formação de professores na universidade, de modo a resgatar a trajetória políticoacadêmica da Faculdade de Educação (FE) como unidade diretamente voltada para a temática da formação de professores.

\section{REPENSANDO A FORMAÇÃO DE PROFESSORES NOS CURSOS DE LICENCIATURA DA UFG}

A discussão sobre a reformulação dos cursos de licenciatura, ao longo das últimas décadas, tem se caracterizado por um embate extremamente fértil no que se refere à natureza, ao caráter e aos desdobramentos norteadores das propostas de formação subjacentes à identidade e às especificidades de tais cursos.

Diferentes proposições sobre a dinâmica organizacional e pedagógica têm possibilitado embates sobre o locus de formação do licenciado e a emergência de projetos com base em três perspectivas distintas:

1) a licenciatura entendida como complementação pedagógica, conhecida como esquema $3+1$

2) a dicotomia bacharelado e licenciatura, acarretando a ênfase em um dos eixos, em detrimento de um projeto articulado de formação;

3) a busca do estabelecimento de uma política de graduação que articule uma base comum para a formação do licenciado, sem negligenciar a relação fecunda e necessária entre bacharelado e licenciatura.

Tais posturas revelam diferentes compreensões de docência e de prática pedagógica, resultando em desdobramentos distintos na formação e no trabalho pedagógico do professor, no cotidiano da educação básica.

De modo geral, assiste-se no país à implementação de políticas governamentais de formação de professores cuja ênfase tem se pautado pela formação em serviço e, em muitos casos, pelo 
aligeiramento da formação inicial, entendida como capacitação pedagógica de cunho estritamente técnico.

Com a aprovação da LDB (Lei n. 9.394/96), e na esteira do processo de diversificação e diferenciação da educação superior, observa-se uma lógica indutora de mudanças na organização e na gestão das instituições de ensino superior no Brasil. Em que pese esse contexto, a UFG, com base em sua identidade institucional e no seu projeto de autonomia, tem a possibilidade histórica de repensar a sua trajetória. Para tanto, deve considerar o seu projeto e as diretrizes emanadas do MEC como indicações legais para a implementação dos projetos pedagógicos dos cursos de licenciaturas nas diferentes áreas, bem como as contribuições oriundas dos diferentes atores sociais que vêm debatendo a temática ao longo das últimas décadas.

Questões como a relação teoria e prática, indissociabilidade entre o ensino e a pesquisa, entre outras, colocam-se como desafios institucionais no processo de reformulação dos cursos de graduação, de modo a efetivar um projeto coletivo de formação que não se reduza a atividades meramente de ensino ou de municiamento prático, centrado na aquisição de habilidades e competências segundo uma concepção de formação e profissionalização restritas.

A formação de professores tem sido, nas duas últimas décadas, um dos temas mais recorrentes na pesquisa educacional, não só brasileira. Também na UFG, predominantemente na FE, já existe uma relativa produção acadêmica, além de um histórico de protagonismo da instituição quanto à formação de professores, caracterizado pela sua participação nos debates nacionais, pela construção de um projeto tido como pioneiro $^{3}$ e pela manutenção da discussão interna e realização de estudos a respeito desse conjunto da atividade formativa. Isso permite afirmar que já existe na UFG uma cultura de formação de professores.

Além da produção teórica que se consolida na área, a reformulação dos cursos de licenciatura demanda a constituição de debates, grupos interdisciplinares de estudo e, conseqüentemente, a implementação de espaços que: a) estimulem a institucionalização da pesquisa sobre essa atividade formativa, desenvolvida nos vários institutos e faculdades; b) desencadeiem o oferecimento de atividades 
198 OLIVEIRA, J. F.; DOURADO, L. F.; GUIMARÃES, V. S. - A reformulação...

acadêmicas sobre a temática, principalmente nos programas de pósgraduação stricto sensu, como já se verifica em muitas universidades; c) consolidem outros locus de discussão e proposição sobre os cursos de formação de professores. Esta parece ser uma via para propiciar a consolidação de uma cultura de formação de professores na instituição e de desenvolvimento de uma identidade para os cursos de licenciatura.

O presente texto indica algumas reflexões sobre a importância política de se estabelecer um projeto acadêmico para os cursos de licenciatura da universidade. Nesse sentido, busca contribuir com o debate que ora se efetiva na instituição, no que concerne à revisão dos projetos pedagógicos dos cursos, considerando a legislação vigente e a reformulação geral dos cursos da UFG.

Antes de se estabelecer a discussão sobre o papel das faculdades ou dos departamentos de educação em relação aos outros cursos de formação de professores, é necessário afirmar a importância do envolvimento efetivo dos professores na construção de projetos pedagógicos que contribuam para a articulação entre as unidades acadêmicas da instituição.

Um dos muitos equívocos presentes na discussão sobre a formação pedagógica de um curso de licenciatura é o entendimento de que esta é uma dimensão da formação, a ser tratada por pedagogos (nas respectivas disciplinas) ou por interessados na área educacional. O que significa a defesa de que a formação pedagógica seria somente um ingrediente a mais na formação. E não é isso. Entende-se, neste texto, que a formação pedagógica equivale ao processo de discussão e construção de consensos possíveis quanto à identidade de cidadão e profissional que se quer formar e quanto aos meios de viabilizá-la. Poder-se-ia dizer que a formação pedagógica indica as mudanças e a identidade que se quer "sugerir" que os futuros professores desenvolvam. Nesse sentido, a formação pedagógica explicita, mobiliza e auxilia na concretização das finalidades formativas da ciência ou área de conhecimento que se ensina, noutras palavras, explicita o componente ético, político e prático dos conhecimentos que atribuem substantividade à formação.

Assim, sem separar conteúdo e forma, a dimensão, digamos, substantiva de cada curso são os métodos e os conteúdos da respectiva 
ciência ou área de estudo em que o futuro professor está se formando. Desse modo, a ênfase na dimensão integradora da formação pedagógica implica assumir que o bacharelado e a licenciatura são cursos com identidades próprias e articulados, contribuindo para superar o entendimento da licenciatura como curso sem identidade, frágil teoricamente, sem pesquisa - atributos que lhes seriam conferidos pelo vínculo com o bacharelado. Assim entendida, a formação pedagógica contribui significativamente para uma dimensão de totalidade na formação do futuro professor.

Embora a identidade formativa de todo curso de licenciatura seja responsabilidade primeira dos sujeitos aí envolvidos, é preciso esforços para se evitar o isolamento com que a formação de professores acontece, de maneira geral, nas várias instituições de ensino superior. Esse isolamento parece propiciar a constituição de entraves e diminuir a possibilidade de se atribuir uma identidade à formação de professores. Sem que os cursos abdiquem de sua responsabilidade, torna-se necessária a discussão do isolamento da formação docente na instituição. Uma possibilidade de superação dessa dificuldade seria a universidade estimular espaços e processos para o intercâmbio de experiências de formação e profissionalização dos licenciandos e, a partir daí, construir parcerias entre os próprios institutos/unidades acadêmicas responsáveis pela formação de professores.

Entende-se que a Faculdade de Educação, pela sua atuação e pelo envolvimento efetivo com a formação de professores, pode e deve contribuir com a dinâmica de reformulação dos cursos de licenciatura, especialmente, sugerindo uma proposta de base comum que tenha por eixo uma concepção ampla de docência que englobe as múltiplas dimensões do trabalho pedagógico por meio de uma sólida formação teórica em todas as atividades curriculares - nos conteúdos específicos a serem ensinados na Educação Básica, em todos os seus níveis e modalidades, e nos conteúdos especificamente pedagógicos -, uma ampla formação cultural e a incorporação da pesquisa como princípio formativo, entre outros.

Buscando-se concretizar o que foi defendido, são propostas duas ações básicas para o processo de elaboração dos projetos curriculares dos cursos de licenciatura: 
200 OLIVEIRA, J. F.; DOURADO, L. F.; GUIMARÃES, V. S. - A reformulação...

a) componentes curriculares fundamentais para a elaboração de projetos para as diversas licenciaturas da universidade;

b) proposta de trabalho para a reformulação curricular dos cursos de licenciatura.

COMPONENTES CURRICULARES FUNDAMENTAIS PARA A ELABORAÇÃO DE PROJETOS PARA AS DIVERSAS LICENCIATURAS DA UFG

A estruturação de um projeto de licenciatura deve considerar a legislação vigente, ${ }^{4}$ regulamento geral de cursos, contribuições do Fórum de Licenciatura e das entidades nacionais da área (Anpae, Anped, Anfope, ForumDir, Fórum de Pró-Reitores de Graduação, Fórum Nacional em Defesa da Escola Pública), em sintonia com o projeto de autonomia da instituição.

A Resolução CNE n. 02/2002, ao estabelecer que os cursos de graduação plena garantam a articulação entre teoria e prática, ao longo do curso, define, entre as dimensões comuns, 400 horas de prática como componente curricular e 400 horas de estágio curricular supervisionado, além de 1800 horas para conteúdos curriculares de natureza científico-cultural e 200 horas para outras atividades acadêmico-científico-culturais. Com base nesses indicadores e nas lutas desencadeadas nacionalmente na área da educação, especificamente, na formação de professores, e buscando um projeto para os cursos de licenciatura da instituição, propõe-se que a estruturação curricular dos referidos cursos contemplem os seguintes componentes curriculares:

1) Didática e prática docente (estágio supervisionado) - 400 horas

Ementa: A didática, seu histórico e objeto de estudo; estágio supervisionado: concepções e práticas; formas de organização, mediação e avaliação do processo ensino-aprendizagem; elaboração, execução e avaliação de projetos de docência para a educação básica; elaboração de propostas de trabalho para diferentes situações da realidade escolar brasileira. 
2) Disciplinas e prática como componente curricular na formação do licenciado

A prática entendida como componente curricular deve ser planejada e desenvolvida ao longo do processo formativo. Nesse sentido, não se reduz à prática de ensino convencionalmente entendida, caracterizando-se como espaço de pesquisa e reflexão das questões postas pela educação e pelo trabalho docente.

Nesse sentido, o Parecer CNE n. 28/2001 compreende

a prática, como componente curricular, que terá necessariamente a marca dos projetos pedagógicos das instituições formadoras, ao transcender a sala de aula para o conjunto do ambiente escolar e da própria educação escolar, pode envolver uma articulação com os órgãos normativos e com os órgãos executivos dos sistemas.

Os componentes curriculares sugeridos, a seguir, com suas respectivas ementas, objetivam indicar disciplinas para os diferentes projetos curriculares em construção, de modo a garantir a formação comum dos licenciados. Os componentes, a serem dispostos ao longo da integralização curricular dos diferentes projetos de cursos de licenciatura, poderão integrar o núcleo de formação pedagógica.

\section{a) Psicologia da Educação}

A psicologia como ciência: seu objeto de estudo e relações sócio-histórico-culturais com a educação; as teorias psicológicas sobre os processos ensino-aprendizagem e desenvolvimento humano em diversos contextos e seus desdobramentos em práticas educativas; desenvolvimento psíquico, emocional e cognitivo da criança ao adulto.

\section{b) Políticas Educacionais}

A relação Estado e políticas educacionais; os desdobramentos da política educacional no Brasil pós-64; as políticas de regulação e gestão da educação brasileira e a (re)democratização da sociedade brasileira; os movimentos de diversificação, diferenciação e avaliação da educação nacional; legislação educacional atual; a regulamentação 
202 OLIVEIRA, J. F.; DOURADO, L. F.; GUIMARÃES, V. S. - A reformulação...

do sistema educativo goiano e as perspectivas para a escola pública em Goiás.

c) Fundamentos Filosóficos e Sócio-Históricos da Educação

A educação como processo social; a educação brasileira na experiência histórica do Ocidente; a ideologia liberal e os princípios da educação pública; sociedade, cultura e educação no Brasil: os movimentos educacionais e a luta pelo ensino público no Brasil, a relação entre a esfera pública e privada no campo da educação e os movimentos da educação popular.

d) Gestão e Organização do Trabalho Pedagógico

Perspectivas de gestão e organização do trabalho pedagógico: concepções e práticas, democratização e autonomia da escola; projeto político-pedagógico; política de formação e profissionalização docentes: formação inicial e continuada, plano de cargos e salários.

e) Cultura, Currículo e Avaliação

Cultura, planejamento, currículo e avaliação: concepções e práticas; avaliação e currículo no Brasil: políticas e implicações para a organização escolar; sistema de avaliação da educação básica; cultura, planejamento e relações de poder na escola.

f) Educação, Comunicação e Mídias

Tecnologia como cultura; tecnologia, consumo e ética; processos educativos mediados por tecnologias; tecnologias e suas implicações na educação; gestão da comunicação e das mídias no ambiente escolar.

PROPOSTA DE TRABALHO PARA A REFORMULAÇÃO CURRICULAR DOS CURSOS DE LICENCIATURA

A construção de um projeto coletivo para a reformulação dos cursos de licenciatura implica o envolvimento de todos os atores institucionais que participam da formação de professores. Nesse sentido, é preciso considerar a ação articulada das seguintes instâncias: 
a) Pró-Reitoria de Graduação;

b) Câmara de Graduação;

c) Fórum de Licenciatura e/ou espaços colegiados de discussão sobre a formação de professores.

Faz-se necessário, também, definir objetivos que possibilitem o aprofundamento do trabalho a ser desenvolvido, tais como:

a) discutir e elaborar, com todas as instâncias envolvidas, as diretrizes e bases da política e do projeto de formação de professores nos cursos de licenciatura da instituição;

b) analisar os documentos legais que estabelecem diretrizes curriculares nacionais para a formação de professores da educação básica, bem como as diretrizes curriculares específicas dos cursos de licenciatura;

c) apoiar a discussão para elaboração dos projetos de reformulação curricular dos cursos de licenciatura em cada instituto, faculdade ou centros;

d) analisar os projetos de reformulação curricular aprovados pelas unidades acadêmicas e oferecer subsídios para uma política de formação dos licenciandos.

Considerando a necessidade de envolvimento das instâncias que atuam nos cursos de licenciatura e, ainda, as especificidades dos cursos, é aconselhável a criação de instância de coordenação ou comissão específica de trabalho. Essa instância ou comissão deve ser composta de professores das diversas unidades envolvidas com os cursos de licenciatura, de modo a estabelecer um plano de trabalho que contemple ações, procedimentos, responsabilidades e cronograma amplamente divulgado na instituição, objetivando a construção de um projeto efetivamente coletivo.

\section{ABSTRACT}

This essay is about the curricular reform of degree courses. The authours, from the critical analysis of the valid legislation about the teachers training and from the experience of the developed reform at the Faculdade de 
204 OLIVEIRA, J. F.; DOURADO, L. F.; GUIMARÃES, V. S. - A reformulação...

Educação/UFG, indicate a possible way for the coletive make up of a teachers training project.

Key-words: curricular reform, teachers training, degree courses.

\section{NOTAS}

3. Trata-se do projeto de formação implantado na FE/UFG em 1984, cuja decisão central foi a suspensão da formação do "especialista" em educação, optando pela formação do professor das séries iniciais do ensino fundamental, por meio do curso de Pedagogia. Além disso, a UFG vivenciou, nesse período, a reformulação dos diferentes cursos de licenciatura de modo integrado, constituindo, à época, um projeto pedagógico.

4. Parecer CNE n. 28/2001, Resoluções CNE n. 01 e n. 02/2002, entre outros.

\section{REFERÊNCIAS}

ANFOPE. Documentos finais dos VI, VII, VIII, IX, X encontros nacionais da Associação Nacional pela Formação dos Profissionais da Educação, 1992, $1994,1996,1998$ e 2000.

BRASIL. Ministério da Educação, Conselho Nacional da Educação. Parecer CNE-CP009/2001.

Parecer CNE-CP 28/2001.

Resolução CNE-CP 01/2002.

Resolução CNE-CP 02/2002.

.Secretaria da Educação Superior. Documento norteador para comissões de autorização e reconhecimento de curso de pedagogia, 2001.

.Secretaria da Educação Superior. Comissão de Especialistas de Pedagogia. Diretrizes curriculares para o curso de pedagogia, 1999. 